\title{
Preliminary assessment of the efficiency of ORC plant operation supplied with hot water from the HDR system
}

\author{
Radomir Kaczmarek ${ }^{1}$, and Aleksander Stachel ${ }^{1, *}$ \\ ${ }^{1}$ West-Pomeranian University of Technology, Szczecin, Department of Heat Enginnering, al. Piastów 17, PL-70-310 Szczecin, Poland
}

\begin{abstract}
The paper presents the results of a theoretical analysis of the low-temperature ORC power plant operation fed with hot water obtained in a hot dry rock (HDR) extraction system. Issues related to the energy content of the Earth interior and its resources are discussed. The principles of acquiring heat in HDR installation are described and examples of installations commissioned in Europe as well as around the world are presented. The appropriate locations for building HDR installations in Poland were also characterized. Presented also is the concept of the ORC power plant supplied with water heated in the HDR rock exchanger. The analysis and evaluation of the ORC/HDR power plant operation supplied with water with parameters possible to obtain in selected locations throughout the country was accomplished. It has been shown that it is possible to build an ORC power plant powered from the HDR resources.
\end{abstract}

\section{Introduction}

Among the so-called renewable energy sources an important one is the geothermal energy defined as the heat resource contained in the interior of the Earth, while the operational significance has the heat accumulated in the rocks forming the Earth's crust. These rocks accumulate heat coming from the Earth's core, as well as the heat from radioactive elements decay processes. As a result, the Earth's crust is a rock structure with a significant energy potential, characterized by high temperature reaching several hundred degrees Celsius [1].

Due to the way in which this energy is accumulated, we divide the resources into:

- hydrothermal - where heat is accumulated in the unrestricted underground reservoir fluids,

- petrothermal - where heat is stored in the hot rocks (also salt dredges).

The heat resources contained in hot liquids (water, steam) can be used for heating purposes, and in the case of high thermal parameters - for generating electricity. Petrothermal resources are considered as prospective source of heat, and of significant importance are energy resources accumulated in the so-called hot dry rocks.

\section{Technology of hot dry rocks}

Hot dry rocks are defined as solid, not very strongly fractured rock structures devoid of reservoir properties and constituting a natural heat reservoir with a temperature above $150^{\circ} \mathrm{C}$. In these layers there are no natural occurrence of water and / or steam resources. The energy potential accumulated in them is possible to be utilised using the appropriate technology, known as the hot dry rock technology, HDR.

In practice, this means acquiring (and using) the heat accumulated in solid crystalline rocks, mainly granite rocks, located at significant depths (up to $5 \mathrm{~km}$ and more), covered with insulating rock layers which poorly conduct the heat.

According to the definition of the Energy Research and Development Administration (US ERDA), HDR heat is defined as "accumulated in rocks at a depth of up to $10 \mathrm{~km}$ from the Earth's surface, from which it can be economically extracted using the natural hot water or steam" [2] .

Due to the efficiency of the process of obtaining heat, the areas useful for creating the HDR systems are:

- young volcanic areas;

- intense heat flow from the inside of the globe;

- significant concentration of radioactive elements constituting spontaneous radioactive sources of heat.

The concept of obtaining energy from hot rock structures was developed in the 1970s and uses natural or artificially created fracture systems developing in the rock mass in a kind of the "non-permeable" heat exchanger connected to the surface by access channels (injection and production wells) $[1,3]$.

Acquisition of heat is attained by injecting a highpressure water into rock structures, which, flowing through an extensive network of cracks picks up heat from the hot rocks. Hot water flows out of the extraction well to the surface, where it transmits the heat it contains to the recipients (Fig. 1). This heat can be used for heating or industrial purposes (e.g. electricity generation). After the heat is removed, the water is again injected back into the bed.

\footnotetext{
${ }^{*}$ Corresponding author: aleksander.stachel@,zut.edu.pl
} 
The HDR extraction system encompasses a bed with a sufficiently high porosity, with an extended heat transfer surface, ensuring good permeability of the injected liquid and its intensive heating. In the case where the rock structure is solid, or if the natural cracks and pores occurring in it do not ensure appropriate flow of the injected water, the permeability of the bed can be improved in the process of so-called hydraulic fracturing.

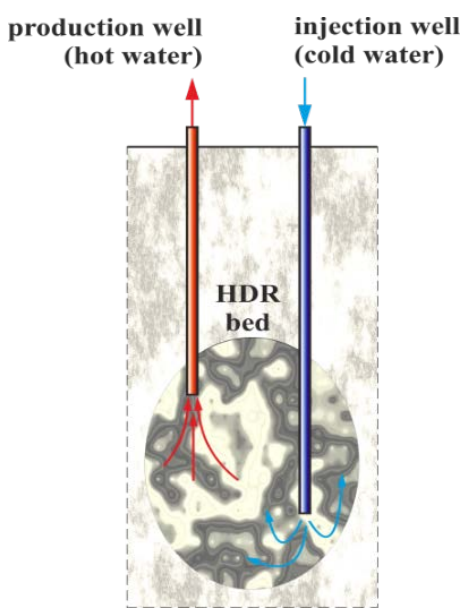

Fig. 1. A concept of the heat exchanger in HDR technology [1].

It should be remembered that the rocks forming the "non-permeable" heat exchanger transmit energy in the transient heat transfer process, while the rate of heat decreases over time as the temperature of the rocks decreases. An important problem is also the mineralization of the outgoing hot water, caused by the dissolution of chemical compounds (salts) contained in the rock massif.

\section{HDR installations worldwide}

The first installation acquiring the heat from dry hot rocks was commissioned in 1973 in Fenton Hill, New Mexico (USA) and was an attempt to develop a fullscale HDR heat exchanger. The installation was based on two boreholes, injecting and extracting ones, reaching a hot, sealed, crystalline granite formation featuring $185^{\circ} \mathrm{C}$, located at a depth of $\sim 2600 \mathrm{~m}$. The rock heat exchanger made it possible to heat the stream of injected water $\left(23-57 \mathrm{~m}^{3} / \mathrm{h}\right)$ to a temperature of $135-140^{\circ} \mathrm{C}$ (Fig. 2) [4].

In the following years, a number of other HDR projects were implemented, including the Hijiori project in Japan [4]. The system was based on two horizontally fractured rock deposits at two different depths, i.e. $1800 \mathrm{~m}$ and $2200 \mathrm{~m}$ respectively, separated by a layer of solid impermeable rock with a thickness of $400 \mathrm{~m}$. Heat reservoirs with a temperature of $250^{\circ} \mathrm{C}$ (upper) and $270^{\circ} \mathrm{C}$ (lower), have been connected with the surface of the Earth by means of injection and extraction ducts. The conducted tests, apart from the hydraulic testing of the HDR system, also included the assessment of the possibility of converting the energy of obtained hot water into electric energy with the aid of ORC installation.

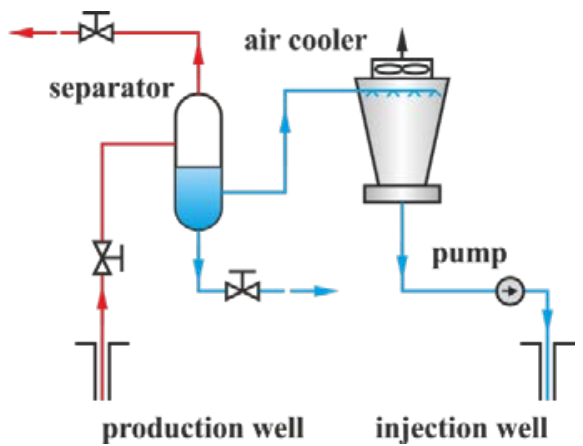

Fig. 2. Simplified schematic of the Fenton Hill HDR testing installation $[4,5]$.

In Europe, the largest research project in the area of utilisation of hot dry rocks is the installation in Soultzsous-Fortes (Alsace, France), the construction of which was initiated in 1987. Its location resulted from the favorable geothermal conditions of the geological and tectonic formation known as the Burgundy Trough, including the forecasted high temperature of rocks $\left(\sim 200^{\circ} \mathrm{C}\right.$ at a depth of $\left.\sim 5 \mathrm{~km}\right)$. The source of heat are the deposits of crystalline rocks covered with a sedimentary rock layer up to $1000 \mathrm{~m}$ thick. The average geothermal gradient of sedimentary rocks is $0.08-0.1 \mathrm{~K} / \mathrm{m}$ and decreases to $0.028-0.05 \mathrm{~K} / \mathrm{m}$ below the granite rocks [4].

Several years of work and research led to the development of the installation whose extraction part consists of one injection well (GPK3) and two extraction wells (GPK2, GPK4), reaching a depth of $\sim 5000 \mathrm{~m}$, where the rock temperature was found to be $\sim 200^{\circ} \mathrm{C}$. The heads of the extraction holes are located near to the head of the injection well, while their lower ends are deviated in opposite directions from it by about $600 \mathrm{~m}$. The heat transfer area of the HDR exchanger created by hydraulic fracturing is estimated at about $3 \mathrm{~km}^{2}$, while its volume - at 2-3 $\mathrm{km}^{3}$.

The installation in Soultz was launched in 2006. The water introduced with the GPK3 injection well is heated from the hot rocks, flowing through the system of cracks and gaps, and then flows to the surface through the GPK2 and GPK4 wells. The heat obtained from the rocks supplies the power plant operating as the organic Rankine cycle, in which isobutane is used as a working fluid (Fig. 3). The ORC power plant was modernized in 2015 and produces the electric power in the amount of $1.7 \mathrm{MW}$ at the efficiency of $11.4 \%$. It is supplied with the flow rate of water $\left(33.3 \mathrm{dm}^{3} / \mathrm{s}\right)$ at a temperature of $160^{\circ} \mathrm{C}$. Water is introduced back to the bed at a temperature of $70^{\circ} \mathrm{C}$. 


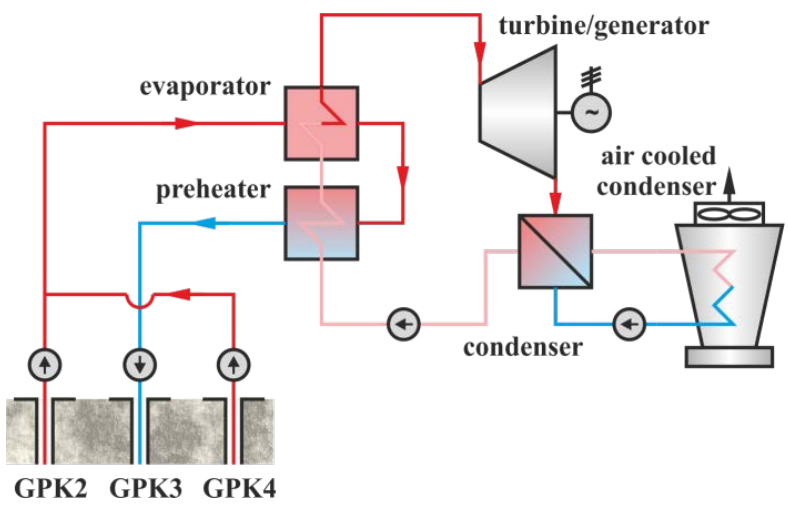

Fig. 3. Simplified schematic of the Soultz-sous-Forets power plant [4,5]: GPK3 - injection well, GPK2, GPK4 - production wells.

\section{Geological conditions of HDR installations in Poland}

Also in Poland, activities are underway to search for the possibility of building an installation for acquiring the heat from hot dry rocks [6,7]. In recent years accomplished has been amongst the others the research grant with the purpose to indicate regions with favorable conditions for the construction of a geothermal installation based on the HDR technology [8]. The project indicates the useful for this purpose locations of hot dry rocks, which should be characterized by a maximum temperature and be placed at the smallest possible depth. In addition, they should feature adequate porosity and permeability, high specific heat and high thermal conductivity, and be susceptible to fracturing processes. These properties have a significant impact on the installation location, as well as its subsequent operation.

Rock structures that are useful for this purpose are related to the occurrence of, among others igneous rocks. Rocks of this type with relatively large heat transfer surfaces and volumetric capacities exist mainly in the Sudety and the Tatra Mountains. Due to environmental reasons, their use is more realistic within the Sudety area, and therefore this area is perceived as the perspective region for the HDR technology. This applies in particular to the Karkonosze granite massifs in which significant heat availability from the inside of the Earth (Cieplice) was determined to be significant, as well as the locally increased emission of radiogenic heat. This applies in particular to the area of Szklarska Poręba, where the heat flux released in the process of radioactive decay (the presence of uranium and thorium isotopes) is extremely high and reaches $4.5-5.0 \mu \mathrm{W} / \mathrm{m}^{3}$, and according to some sources even $7.0 \mu \mathrm{W} / \mathrm{m}^{3}$. The temperature distribution model developed for this area, taking into account relatively high values of the geothermal gradient, estimates the rock temperatures from $145^{\circ} \mathrm{C}$ (at a depth of $3.5 \mathrm{~km}$ ), to $225^{\circ} \mathrm{C}$ in the north-east zone (at a depth of $5.5 \mathrm{~km}$ ). This renders that the location of HDR installations within the Karkonosze area seem to be exceptionally promising $[7,8,9]$.

It is believed that the second constructive area for obtaining heat from hot dry rocks may be the area to the west of Gorzów Wielkopolski, in particular the vicinity of Lubuskie Dębno, characterized by a heat flux of geothermal heat equal to $100 \mathrm{~mW} / \mathrm{m}^{2}$ and a high value of geothermal gradient (about $40 \mathrm{~K} / \mathrm{km}$ ). This allows to conclude that at the depth of 3-5 km there can be expected a relatively high temperature.

However, it should be borne in mind that the indicated rock structures may be subject to a significant error, both due to geological conditions and predicted temperatures, associated with the variable value of geothermal gradient and measurement uncertainties. Therefore, final location decisions should be supported by in situ research, enabling the verification of geological, thermal, physical and chemical conditions.

\section{A concept of ORC / HDR power plant for the Polish conditions}

Apart from geological analyzes, important due to the specific requirements facing the rock structures and useful for the construction of HDR systems, works are also underway to assess the feasibility and rationale of construction of the ORC power plant powered by the hot dry rock energy.

Due to the estimated temperatures of the water supplied from the HDR system, it is assumed that the hypothetical power plant should operate according to the Clausius-Rankine (C-R) thermodynamic cycle with the low boiling point organic fluid. The choice of technology is dictated by the relatively low temperature of the feed water. The conversion of heat obtained in a traditional power plant, in which the water / steam is the working fluid, would be ineffective from the energy conversion point of view.

Schematic diagram of the ORC power plant is shown in Fig.4. The power plant consists of two heat exchangers, namely the preheater $(\mathrm{PH})$ and evaporator (EV), a turbogenerator (TG), a condenser (CO) and a circulating pump (P). Hot water from the HDR system is fed to the evaporator (EV), where the heat contained in it is transferred to the working fluid of the cycle, causing its evaporation. Part of the water flow rate $\left(\mathrm{m}_{\mathrm{s} 1}\right)$ leaving the evaporator $(\mathrm{EV})$ is directed to the preheater $(\mathrm{PH})$. Both streams $\left(\mathrm{m}_{\mathrm{s} 1}+\mathrm{m}_{\mathrm{s} 2}\right)$, after recombination, are injected into the HDR structure.

The working fluid, heated in the preheater and vaporised in the evaporator, is directed to the turbine, where it expands and generates work. After expansion and condensation in the condenser, the fluid is again pumped into the heater - evaporator system.

In ORC power plants, various organic substances with a low boiling point and appropriate thermophysical, operational and environmental properties are used as working fluids. The recommendations for their 
selection are given in numerous literature on the subject, for example in $[4,5,10]$.

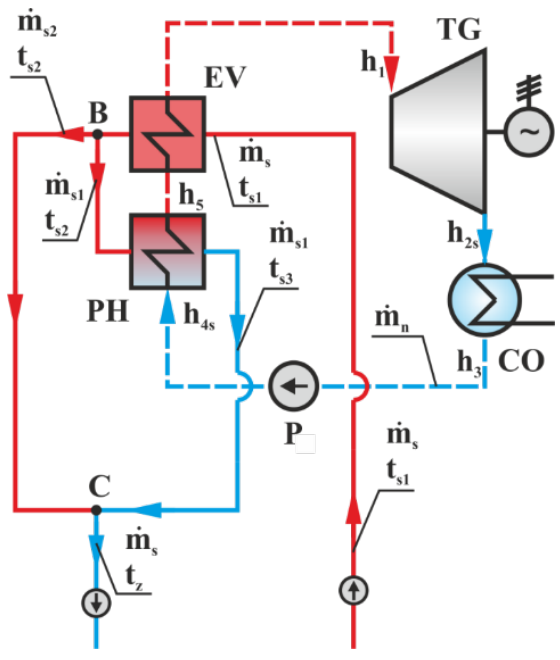

Fig. 4. A schematic diagram of the ORC power plant supplied with heat from the HDR deposits.

\section{Analysis of ORC power plant}

Initial evaluation of the operation of a hypothetical ORC power plant fed with hot water from the HDR deposit, was referred to the installation shown schematically in Fig. 5 A number of assumptions have been made in the calculations, among others that:

- power plant works according to the subcritical cycle;

- temperature of water supplied to the evaporator is $\mathrm{t}_{\mathrm{s} 1}=130-180^{\circ} \mathrm{C}$, which results from the predicted thermal parameters of HDR systems, possible to achieve in Poland;

- condensation of the working fluid vapor in the condenser proceeds at a pressure corresponding to the condensing temperature, $\mathrm{t}_{\mathrm{h} 3}=30^{\circ} \mathrm{C}$;

- temperature differences between heating and working fluids in the heater and evaporator are defined in Fig. 5;

- calculations of C-R cycle power were related to the unit water flow rate supplied from the HDR system, $\dot{m}_{s}=1 \mathrm{~kg} / \mathrm{s}$;

- geothermal water mineralization, $\mathrm{S}=120 \mathrm{~g} / \mathrm{kg}$;

- five working fluids are included in the calculations.

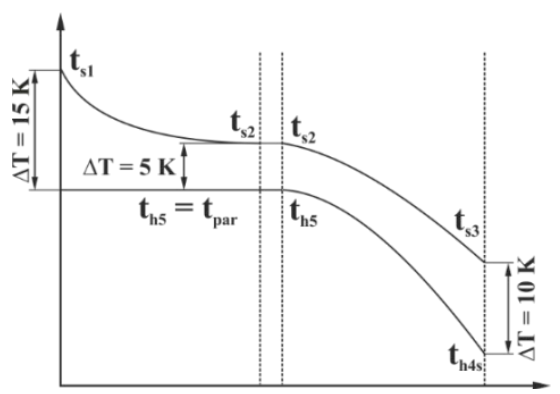

Fig. 5. Temperature distribution in evaporator and preheater.

On the basis of the assumptions made, the assessment of the power plant operation was carried out, specifying, among others, the power and efficiency of the C-R cycle, including:
- type of working fluid,

- temperature changes of geothermal water,

- extent of the flow rate and the degree of mineralization of water supplied to the system $\dot{m}_{s}$.

Thermodynamic parameters of the considered working fluids at individual nodes of the $\mathrm{C}$-R cycle were determined using the Refprop software [11].

\section{Methodology of calculations}

The purpose of calculations of the hypothetical ORC power plant was to determine the achievable power and efficiency of the Clausius-Rankine cycle, at the assumed feeding and operation parameters. The calculations were based on the following relations.

The mass flow rate of the low-boiling point fluid in the boiler leg was determined from the evaporator energy balance equation:

$$
\dot{m}_{n}=\frac{\dot{m}_{s} c_{w}\left(t_{s 1}-t_{s 2}\right)}{h_{1}-h_{5}}
$$

The mass flow rate of water $\dot{m}_{s 1}$ from the evaporator energy balance for the water leg yields:

$$
\dot{m}_{s 1}=\frac{\dot{m}_{n}\left(h_{5}-h_{4 s}\right)}{c_{W}\left(t_{s 2}-t_{s 3}\right)}
$$

whereas the mass flow rate of unused water directed to the HDR system was determined from the mass balance for the node „B”:

$$
\dot{m}_{s 2}=\dot{m}_{s}-\dot{m}_{s 1}
$$

Temperature of injected water was determined on the basis of the energy balance equation for the node „C":

$$
t_{z}=\frac{\dot{m}_{s 1} t_{s 3}+\dot{m}_{s 2} t_{s 2}}{\dot{m}_{s}}
$$

Subsequent quantities characterizing the ORC power plant have been referenced to the unit water flow rate acquired from the HDR system $(1 \mathrm{~kg} / \mathrm{s})$, by means of:

- heat rate supplied to the ORC system in evaporator and heater:

$$
\dot{Q}_{d}=\dot{m}_{n}\left(h_{1}-h_{4 s}\right)
$$

- heat rate removed from the system in the condenser:

$$
\dot{Q}_{W}=\dot{m}_{n}\left(h_{2 s}-h_{3}\right)
$$

- theoretical power of turbine:

$$
N_{t}=\dot{m}_{n}\left(h_{1}-h_{2 s}\right)
$$

- theoretical power of the circulation pump:

$$
N_{p}=\dot{m}_{n}\left(h_{4 s}-h_{3}\right)
$$

On that basis calculated was:

- unit power of ORC cycle referred to the assumed flow rate of water acquired in the HDR system $\operatorname{HDR}(1 \mathrm{~kg} / \mathrm{s})$ : 


$$
N_{C R}=N_{t}-N_{p}
$$

- theoretical efficiency of C-R cycle:

$$
\eta_{C R}=\frac{N_{C R}}{\dot{Q}_{d}} 100 \%
$$

In addition, in the calculations considered was the influence of specific heat of water supplied from the HDR system on the resulting power of the C-R cycle. Specific heat depending on the degree of its mineralization, that is, the amount of dissolved compounds (salts).

\section{Results of calculations}

Based on the assumed output data, the power and efficiency calculations of a hypothetical ORC power plant cooperating with the HDR system were made. The calculations were made for five selected working fluids to be used in the power cycle (isohexane, isopentane, pentane, R245ca, R365mfc), as well as for different values of the supply water temperature delivered from the HDR exchanger. The aim was to demonstrate the influence of various working fluids as well as various power parameters on the efficiency of installation operation. The calculations were carried out with the assumption of a unit flow rate of water feeding the power plant cycle.

Sample results of calculations related to one of the considered working fluids in the ORC (iso-hexane) power plant are presented in Table 1 .

Table 1. Sample results of calculations of ORC power plant (isohexane, $\mathrm{T}_{\mathrm{skr}}=30^{\circ} \mathrm{C}, \mathrm{T}_{\mathrm{kr}}=224,55^{\circ} \mathrm{C}$ ).

\begin{tabular}{|c|c|c|c|c|c|c|}
\hline$t_{e v}$ & $c_{w}$ & $h_{1}$ & $h_{2 \mathrm{~s}}$ & $h_{3}$ & $h_{4 \mathrm{~s}}$ & $h_{5}$ \\
\hline${ }^{\circ} \mathrm{C}$ & $\begin{array}{c}\mathrm{kJ} / \\
(\mathrm{kg} \cdot \mathrm{K})\end{array}$ & $\mathrm{kJ} / \mathrm{kg}$ & $\mathrm{kJ} / \mathrm{kg}$ & $\mathrm{kJ} / \mathrm{kg}$ & $\mathrm{kJ} / \mathrm{kg}$ & $\mathrm{kJ} / \mathrm{kg}$ \\
\hline 115 & 3,663 & 417,85 & 334,04 & $-70,58$ & $-69,95$ & 140,6 \\
\hline 125 & 3,665 & 435,41 & 343,04 & $-70,58$ & $-69,79$ & 168,21 \\
\hline 135 & 3,668 & 452,90 & 352,24 & $-70,58$ & $-69,59$ & 196,50 \\
\hline 145 & 3,671 & 470,23 & 361,53 & $-70,58$ & $-69,36$ & 225,51 \\
\hline 155 & 3,675 & 487,28 & 370,81 & $-70,58$ & $-69,10$ & 255,31 \\
\hline 165 & 3,679 & 503,90 & 379,93 & $-70,58$ & $-68,79$ & 285,99 \\
\hline
\end{tabular}

\begin{tabular}{|c|c|c|c|c|c|c|c|}
\hline $\mathrm{t}_{\mathrm{ev}}$ & $t_{s 1}$ & $t_{s 2}$ & $t_{s 3}$ & $t_{z}$ & $\dot{m}_{s 1}$ & $\dot{m}_{s 2}$ & $\dot{m}_{n}$ \\
\hline${ }^{\circ} \mathrm{C}$ & ${ }^{\circ} \mathrm{C}$ & ${ }^{\circ} \mathrm{C}$ & ${ }^{\circ} \mathrm{C}$ & ${ }^{\circ} \mathrm{C}$ & $\mathrm{kg}_{\mathrm{s}} / \mathrm{s}$ & $\mathrm{kg}_{\mathrm{s}} / \mathrm{s}$ & $\begin{array}{c}\mathrm{kg}_{\mathrm{n}} / \\
\mathrm{kg}_{\mathrm{s}}\end{array}$ \\
\hline 115 & 13 & 120 & 40 & 1 & & 0,91 & 0,13 \\
\hline 125 & 140 & 130 & 40 & 21,09 & 0,1 & 0,9 & 0,14 \\
\hline 135 & 150 & 140 & 40 & 129,62 & 0,1 & 0,90 & 0,14 \\
\hline 145 & 160 & 15 & 10 & 37,95 & 0,1 & 0,89 & 0, \\
\hline 155 & 170 & 160 & 40 & 146,01 & 0,1 & 0,88 & 0 \\
\hline 165 & 180 & 170 & 40 & 153,72 & 0,13 & 0,87 & 0,17 \\
\hline
\end{tabular}

Table 1: continuation.
Table 1: continuation.

\begin{tabular}{|c|c|c|c|c|c|c|}
\hline $\mathrm{t}_{\mathrm{ev}}$ & $\dot{Q}_{d}$ & $\dot{Q}_{w}$ & $N_{t}$ & $N_{p}$ & $N_{C R}$ & $\eta_{C R}$ \\
\hline${ }^{\circ} \mathrm{C}$ & $\begin{array}{c}\mathrm{kW} / \\
\left(\mathrm{kg}_{\mathrm{s}} / \mathrm{s}\right)\end{array}$ & $\begin{array}{c}\mathrm{kW} / \\
\left(\mathrm{kg}_{\mathrm{s}} / \mathrm{s}\right)\end{array}$ & $\begin{array}{c}\mathrm{kW} / \\
\left(\mathrm{kg}_{s} / \mathrm{s}\right)\end{array}$ & $\begin{array}{c}\mathrm{kW} / \\
\left(\mathrm{kg}_{\mathrm{s}} / \mathrm{s}\right)\end{array}$ & $\begin{array}{c}\mathrm{kW} / \\
\left(\mathrm{kg}_{\mathrm{s}} / \mathrm{s}\right)\end{array}$ & $\%$ \\
\hline 115 & 64,44 & 53,45 & 11,07 & 0,08 & 10,99 & 17,05 \\
\hline 125 & 69,30 & 56,74 & 12,67 & 0,11 & 12,56 & 18,13 \\
\hline 135 & 74,74 & 60,49 & 14,40 & 0,14 & 14,26 & 19,08 \\
\hline 145 & 80,94 & 64,82 & 16,31 & 0,18 & 16,12 & 19,92 \\
\hline 155 & 88,14 & 69,92 & 18,45 & 0,24 & 18,21 & 20,67 \\
\hline 165 & 96,68 & 76,05 & 20,93 & 0,30 & 20,63 & 21,33 \\
\hline
\end{tabular}

The influence of the type of used working fluid and the feed water temperature on the extent of C-R cycle power output is shown in Fig. 6. For all considered feedwater temperatures, the highest cycle power was obtained for R245ca whereas the smallest one for isohexane.

The C-R circuit power increases with the increase of the feeding temperature (increase of the evaporating temperature of the fluid). The highest values of power were obtained at $180^{\circ} \mathrm{C}$ (evaporating temperature $155^{\circ} \mathrm{C}$ ), whereas the lowest ones at $130^{\circ} \mathrm{C}$ (evaporating temperature $115^{\circ} \mathrm{C}$ ). It should be noted that in the case of the working fluid R245ca, as the temperature rises, a much larger increase in power is observed compared to other working fluids. It can be therefore concluded that both the parameters of water supplied from the HDR system (temperature) and the type of working fluid used have a significant impact on the operation of the power plant and the power obtained in it.

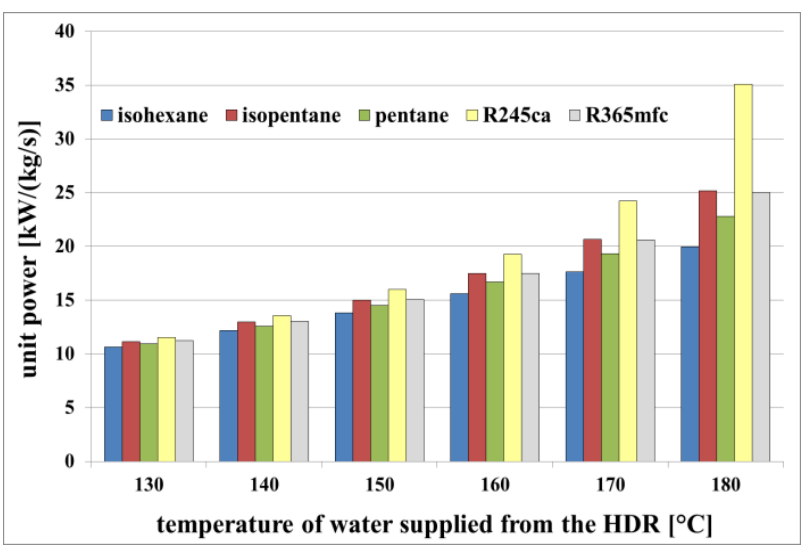

Fig. 6. Attained ORC power in function of the type of working fluid and temperature of water supplied from the HDR system (with reference to $1 \mathrm{~kg} / \mathrm{s}$ of water).

In Fig. 7 presented is the distribution of ORC's efficiency on the type of working fluid used and the temperature of the feed water.

The highest theoretical efficiency of the C-R cycle was obtained for pentane, while the lowest for the R365mfc working fluid. In turn, the fluid R245ca, which achieves the highest power in the entire range of considered temperatures, shows at the same time the lowest efficiencies. It should be also noted that with the same conditions of supply (temperature), the efficiencies of 
the power plant operating with various fluids are close to each other. At the same time, they increase with temperature of the supplied water, and thus the evaporation temperature.

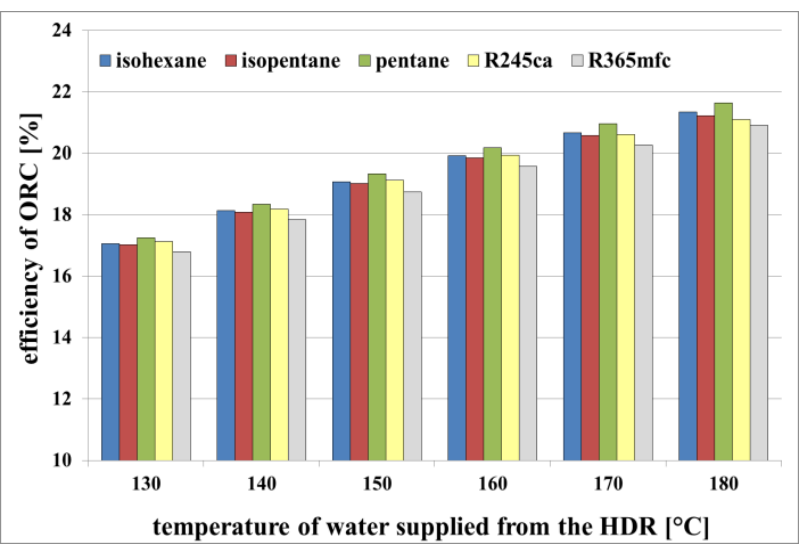

Fig. 7. Efficiency of ORC in function of working fluid and temperature of supply water from the HDR system (with reference to $1 \mathrm{~kg} / \mathrm{s}$ of water).

The next graph (Fig. 8) shows the dependence of the $\mathrm{C}-\mathrm{R}$ cycle power on the degree of mineralization of water supplied to the power plant from the HDR exchanger. The specific heat of water depends on mineralization (salinity), the lower the salinity, the higher its value. Mineralization of water results from the process of dissolving chemical compounds contained in rocks in water injected into the HDR bed, during its flow through the cracks and slots of the rock structure. Increasing mineralization causes a decrease in the flow of the working fluid circulating in the turbine cycle, which in turn results in the reduction in the power of the cycle.

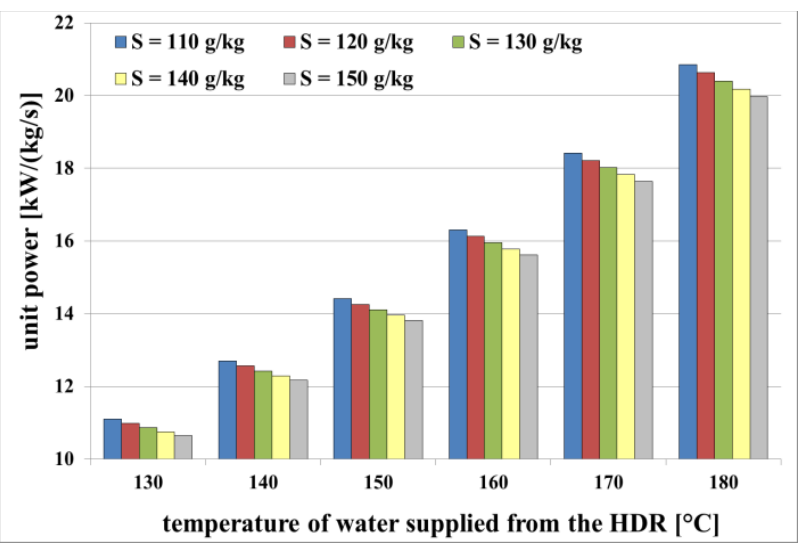

Fig. 8. Influence of mineralization of the supply water from the HDR exchanger on the power of ORC (for isohexane).

An important element of the ORC power plant operation is also the condensation temperature of the vapour leaving the turbine. Heat removal in the condenser is most often carried out with the aid of cooling water supplied from the natural watercourses (river, lake). In the absence of water, so-called cooling towers are used. Cooling with water allows for lower condensing temperatures than in the case of cooling towers. Lower condensing temperature allows to attain higher power installation as well as higher cycle efficiency (Fig. 9).

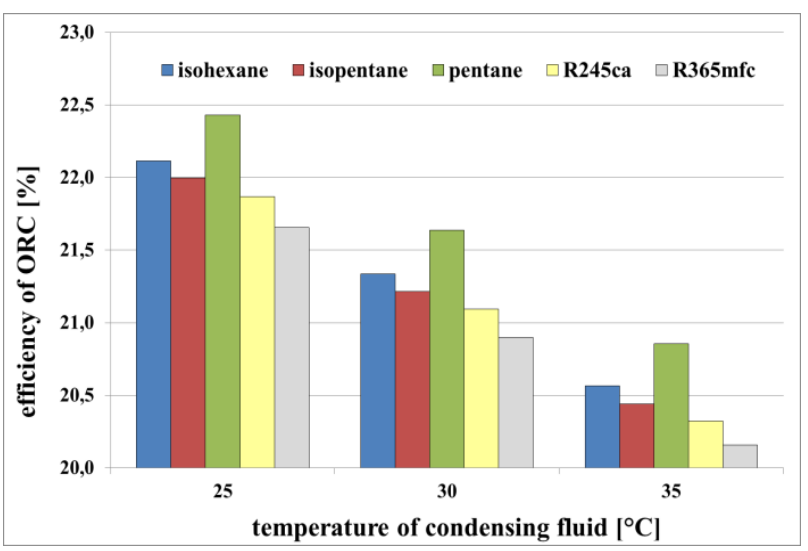

Fig. 9. Influence of condensing temperature on the efficiency of $\mathrm{C}-\mathrm{R}$ cycle in relation to the type of working fluid (evaporation temperature of the working medium: $165^{\circ} \mathrm{C}$ ).

The last important element of the ORC power plant operation evaluation is the influence of the extent of the water flow rate supplied from the HDR deposit. Increasing the water flow rate allows to get more power, and therefore more electricity. The decisive factor here are here the geological and hydraulic properties of the HDR rock exchanger.

\section{Summary and final conclusions}

The work discusses the principles of obtaining heat in HDR systems. Examples of such installations have been characterized. The required geological conditions were discussed and potential locations for construction of such types of installations in Poland were presented. On the basis of the assumed water supply parameters, the power and efficiency calculations of a hypothetical ORC power plant supplied from the HDR system were made, taking into account various working fluids as well as different temperatures of water supplied from the geothermal exchanger.

The conducted analyzes show that in Poland there exist favorable conditions for acquisition of heat from the so-called hot dry rocks [11]. In turn, the calculations and the results obtained prove that it is possible to build a geothermal power plant based on the low-temperature ORC cycle, supplied with heat from the HDR system. The theoretical power of such a power plant, supplied with water with the flow rate of $50 \mathrm{~kg} / \mathrm{s}$ and temperature $180^{\circ} \mathrm{C}$, is estimated at $\mathrm{N}_{\mathrm{CR}}=1500 \mathrm{~kW}$.

However, it should be taken into account that the construction of the ORC power plant cooperating with the HDR system is a complex process, especially in the part concerning the construction of the HDR exchanger. Therefore, the investment decision should be preceded by thorough in-situ testing, enabling the verification of geological, thermal, physical and chemical conditions, as well as detailed analyzes of the fluids affecting the effectiveness and profitability of the planned project. 


\section{References}

1. W. Nowak, R. Sobański, M. Kabat, T. Kujawa, Systems for acquiring and utilizing geothermal energy (Publishing House of Szczecin University of Technology, 2000, in Polish)

2. H. Gupta, S. Roy, Geothermal energy: an alternative resource for the $21^{\text {st }}$ century (Elsevier, Amsterdam, 2007)

3. D.W. Brown, D.V. Duchane, G. Heiken, V. Hriscu, Mining the earth's heat: hot dry rock geothermal energy (Springer Verlag, Berlin, 2012)

4. R. DiPippo, Geothermal power plants. Principles, applications, case studies and environmental impact (Elsevier, Amsterdam, 2008)

5. A. A. Stachel, The use of the energy of the interior of the Earth (Publishing House of West Pomeranian Univ. of Technology, Szczecin, 2013, in Polish)

6. M. Plewa, S. Plewa, Analysis of the possibilities of using the geothermal energy of dry hot rocks in Poland, [in:] Possibilities of using the geothermal water in Poland, with particular emphasis on the Mogilno-Łódź synklinorium. (AGH, Ślesin-Kraków, 1990, pp. 171-181, in Polish)

7. R. Skrzypczak: Proposals for research of location for the needs of geothermal hot dry rock technology in the Sudety region. Technika PGGZR, 50, 1-2, pp. 93-108 (2011, in Polish)

8. Assessment of potential, thermal balance and prospective geological structures for the needs of closed geothermal systems (Hot Dry Rocks) in Poland. Final report. The work commissioned by the Ministry of Environment of the Republic of Poland (Warszawa / Kraków, 2013 (in Polish)
9. J. Szewczyk, D. Gientka, Terrestrial heat flow density in Poland - a new approach. Geological Quarterly, 53, 1 (2010).

10. W. Nowak, A. Stachel, A. Borsukiewicz-Gozdur: Applications of renewable energy sources (Publishing House of Szczecin Univ. of Technology, 2008, in Polish).

11. Refprop 9.1, Standard Reference Database 23, v. 9.1, Reference Fluid Thermodynamic and Transport Properties. National Institute of Standards and Technology, Gaithersburg, MD, USA 2013.

\section{Nomenclature}

$\begin{array}{lll}c_{w} & \text { specific heat capacity } & \mathrm{kJ} /(\mathrm{kgK}) \\ h & \text { specific enthalpy } & \mathrm{kJ} / \mathrm{kg} \\ \dot{m} & \text { mass flow } & \mathrm{kg} / \mathrm{s} \\ N & \text { power } & \mathrm{kW} \\ \dot{Q} & \text { heat flow } & \mathrm{kW} \\ S & \text { mineralization } & \mathrm{g} / \mathrm{kg} \\ T, t & \text { temperature } & \mathrm{K},{ }^{\circ} \mathrm{C} \\ \eta & \text { efficiency } & \%\end{array}$

\section{Subscripts:}

$C R \quad$ refers to the Clausius-Rankine cycle

$d \quad$ refers to the heat supplied

$e v \quad$ refers to the evaporation process

$n \quad$ refers to the working medium

$p \quad$ refers to the pump

$s \quad$ refers to geothermal water (heating water)

$t \quad$ refers to a turbine

$w \quad$ refers to the heat removed

$1,2 s, .$. refers to the characteristic points of the CR cycle 